\title{
Daseinsanálise e psicanálise: caracterização de como se dá esse debate na
} atualidade $^{1}$

\author{
Daseinsanalysis and psychoanalysis: description of how this debate takes \\ place today
}

\author{
Caroline Garpelli Barbosa ${ }^{2}$ \\ Érico Bruno Viana Campos ${ }^{3}$ \\ Carmen Maria Bueno Neme ${ }^{4}$
}

\begin{abstract}
Resumo: Este estudo objetiva retomar o diálogo efetuado entre a tradição da ontologia hermenêutica heideggeriana e a psicanálise freudiana, a fim de caracterizar como ele tem sido realizado na atualidade. Apesar de existirem muitos argumentos que questionam a possibilidade de articulação entre esses dois campos, eles não encerram consensualmente essa discussão e exigem ser atualizados. No cenário mais recente, algumas pesquisas têm acenado para o estabelecimento de pontos de conexões entre elas, sem, contudo, desconsiderarem a especificidade dos campos teóricos em questão. Essa forma de interlocução parece o grande desafio aos pesquisadores na atualidade.
\end{abstract}

Palavras-chave: psicoterapia existencial; psicanálise; Heidegger, Martin, 1889-1976; Freud, Sigmund, 1856-1939; epistemologia.

\begin{abstract}
This study aims to exam the dialogue between Heidegger's hermeneutic ontology and Freud's psychoanalysis theoretical traditions, in order to describe how it has been carried out currently. Despite having a lot of arguments which question the possibility of integration between both fields, they do not enclose consensually this debate and require an updating. In the recent scenario, some researches go towards the establishment of connection points among them, without, however, disregarding the specificity of the involved theoretical fields. This way of consideration of the matter seems to be the great challenge for researchers nowadays.
\end{abstract}

Keywords: existencial psychology; psychoanalysis; Heidegger, Martin, 1889-1976; Freud, Sigmund, 1856-1939; hermeneutics.

\footnotetext{
${ }^{1}$ Este trabalho é parte da pesquisa de Doutorado da primeira autora e tem financiamento CAPES.

${ }^{2}$ Doutorado pelo Programa de Pós-Graduação em Psicologia do Desenvolvimento e Aprendizagem, UNESPBauru; Professora da Universidade Paulista (UNIP - Sorocaba) e da Faculdade Anhanguera de Sorocaba.

${ }^{3}$ Professor Assistente Doutor do Departamento de Psicologia e orientador no Programa de Pós-Graduação em Psicologia do Desenvolvimento e Aprendizagem, UNESP-Bauru.

${ }^{4}$ Professora Adjunta Aposentada do Departamento de Psicologia e orientadora no Programa de Pós-Graduação em Psicologia do Desenvolvimento e Aprendizagem, UNESP-Bauru.
} 


\section{Introdução}

O fim do século XIX foi marcado pelo processo de reestruturação do campo epistemológico em vigor até aquela época, quando se iniciou a conhecida querela dos métodos, caracterizada pela disputa entre as ciências da natureza e as ciências humanas. Tal confronto se iniciou a partir dos questionamentos lançados por alguns filósofos, como Wilhelm Dilthey, em relação à pertinência ou não em se aplicar e estender o método de ciência da física moderna a campos como os das ciências sociais, história, direito etc. Grande parte da questão girava em torno de argumentar se o método das ciências duras seria compatível com a especificidade do objeto estudado pelas ciências humanas, que seria de natureza ontológica diferente daquele estudado pelas ciências naturais (Assoun, 1983; Simanke, 2003).

Embora o saber psicanalítico tenha se constituído exatamente em meio a este momento de reestruturação, Sigmund Freud nunca foi amante das discussões epistemológicas, pois sempre considerou, sem hesitação, a psicanálise como uma ciência da natureza (Freud, 1933/2010a). A posição de Freud em ignorar a querela dos métodos, todavia, não isentou a psicanálise de ser lançada em meio a inúmeras discussões epistemológicas. Diante da provocação freudiana de que o sujeito não encontra seu fundamento na razão e sim no inconsciente, filósofos e outras ciências viram na psicanálise um grande desafio e um vasto campo a ser interrogado, de modo que não foram poucos os que exigiram dela um melhor esclarecimento dos fundamentos que estariam na base de sua teoria e técnica (Assoun, 1983). Essa linha de argumentação e crítica foi seguida, em particular, por grande parte dos autores pertencentes à tradição fenomenológica inaugurada por Edmund Husserl.

Um dos pioneiros nesse sentido foi o psiquiatra suíço Ludwig Binswanger, fundador da Daseinsanálise psiquiátrica, o qual, influenciado pela leitura da obra husserliana e pela ontologia hermenêutica descrita pelo filósofo Martin Heidegger (18891976), procurou refundar a metapsicologia freudiana em bases existenciais. O posicionamento de Binswanger em relação à obra de Freud representa, em grande medida, a tendência que a tradição germânica seguiu em suas críticas dirigidas à psicanálise, que consistiu em criticar a herança materialista, mecanicista, determinista e naturalista da metapsicologia, a fim de lhe oferecer outra base epistemológica (Assoun, 1983). O mesmo pode-se dizer em relação à obra de outro psiquiatra suíço, o também 
daseinsanalista Medard Boss (1903-1990), o qual, convencido das implicações que a obra de Heidegger traria para a psiquiatria, passou a interrogar a psicanálise freudiana à luz dessa perspectiva, com o objetivo de investigar se psicanálise e daseinsanálise teriam algo em comum. Tal tentativa, contudo, não o impediu de também criticar duramente o naturalismo presente na metapsicologia freudiana.

Desde esses diálogos iniciais, muitas batalhas epistemológicas foram iniciadas entre estes dois campos de conhecimento, sendo nesse contexto que se encontra a chave central para a compreensão, não apenas das críticas da fenomenologia à psicanálise, como também as primeiras tentativas de aproximação entre esses dois campos (Assoun, 1983).

Embora se trate de um diálogo que durante algum tempo manteve-se adormecido por ser considerado infrutífero ou mesmo esgotado, é certo que diante dele não é possível ficar indiferente. Não por acaso, ainda na atualidade é possível observar uma série de trabalhos que conjugam esses dois campos mediante uma variedade de temas e autores. Exemplo disso é o livro organizado por Beaune (1998), que reúne mais de vinte trabalhos nessa direção. Além deste, vários outros estudos recentes fazem esta ponte, destacando os possíveis pontos de encontro e distanciamentos entre os autores da fenomenologia e do existencialismo com os da psicanálise. Entre eles, é possível citar os trabalhos de Dutra (2000), Bernet (2002), Lutereau e Kripper (2012), que discutem a noção de inconsciente para Husserl e Freud. Há também os estudos que buscam articular as ideias de Winnicott com a de Heidegger. Entre estes, os mais conhecidos são os trabalhos de Loparic (1999a; 1999b; 2007); Santos (2005; 2010) e Cabestan (2010). Ainda partindo de uma articulação com o pensamento heideggeriano, encontram-se também uma série de trabalhos em discussão com a teoria de Lacan, em especial, articulando a noção de inconsciente à concepção filosófica de verdade (Nancy \& Lacoue-Labarthe, 1991; Richardson, 2003; Meyer, 2009; Lutereau, 2011). Outro eixo de discussão que aparece com certa recorrência é em torno da aproximação que Merleau-Ponty estabeleceu com as ideias de Freud (Duportail, 2006; Beaulieu, 2009; Ayouch, 2009; 2012). Embora a menção aos trabalhos citados não vise esgotar as produções existentes na área, elas ajudam a perceber que o diálogo entre essas duas tradições está distante de ter sido esquecido.

Tendo em vista que essas duas escolas são campos amplos e multifacetados, e que, por isso, trazem dentro de seus respectivos corpos teóricos divergências significativas entre si, será preciso fazer um recorte de modo a estabelecer de que psicanálise e de que filosofia fenomenológico-existencial este estudo trata. Desse modo, o objetivo deste 
artigo, um ensaio teórico baseado em uma revisão narrativa de literatura, é retomar o diálogo efetuado pela tradição da ontologia hermenêutica heideggeriana com a psicanálise, a fim de discutir qual a natureza dele e apresentar o seu status na atualidade. Para tanto, o percurso a ser realizado aqui se deterá na relação estabelecida entre a psicanálise freudiana e a daseinsanálise, com o intuito de questionar se este diálogo ainda tem lugar e como ele tem sido construído.

\section{Caminhos iniciais da fenomenologia e da psicanálise}

Alguns anos antes da efetivação do diálogo entre fenomenologia e psicanálise, especificamente no ano de 1900, essas duas escolas, a partir de seus fundadores, Edmund Husserl (1859-1938) e Sigmund Freud (1956-1939), já traziam a público suas obras fundamentais. Assim, nas "Investigações Lógicas" e em "A interpretação dos sonhos", Husserl (1900/2012) e Freud (1900/1996), respectivamente, apresentaram as bases das escolas que desenvolveram. As coincidências cronológicas e a influência filosófica comum que partilharam, contudo, não impediram que eles seguissem seus caminhos de modos independentes e com interesses muito distintos entre si (Assoun, 1976/2009; Zahavi, 2015). Por este motivo, demarcar a diferença entre esses dois campos de conhecimento, quais são seus objetos de estudo e qual método adotam, é essencial para a compreensão da natureza da crítica que, inicialmente, a tradição fenomenológica direciona à psicanálise.

Husserl desenvolveu a fenomenologia em meio a debates sobre a lógica e a aritmética e teve como propósito inicial o desenvolvimento de um método que permitisse à filosofia lidar com alguns dos problemas epistemológicos presentes nas ciências. A tarefa inicial da fenomenologia deveria ser ajudar as ciências a ancorarem seus saberes em uma concepção racional de verdades e valores que fosse universalmente válida, sendo necessário, para isso, afastar-se de toda e qualquer forma de psicologismo, isto é, das tentativas de fundamentar conhecimentos universais em algo contingente, empírico e particular, como o psiquismo. Nesse sentido, o que importava para Husserl era encontrar um novo fundamento para as teorias do conhecimento em geral e fazer da fenomenologia uma ciência originária, capaz de fundamentar todas as outras (Goto, 2008).

A despeito dos diferentes momentos de elaboração pelos quais passou a fenomenologia husserliana, a proposta do autor sempre girou em torno da necessidade de 
buscar um conhecimento, o qual, para ser seguro, não poderia partir de suposições teóricas de outros campos de estudo (metafísica, naturalismo etc.), mas sim de um estudo detalhado e rigoroso das estruturas da consciência, as quais poderiam ser acessadas desde que se adotasse um método adequado para descrevê-las. Dessa forma, quando Husserl elege a consciência como tema central da fenomenologia, o que está em questão é seu argumento de que é por meio da descrição das experiências que é possível compreender o que algo é e como é, e, assim, obter a evidência necessária e constituinte das várias formas de conhecimento (Zahavi, 2015). Nesse sentido, todo empreendimento de desenvolver um método que lhe permitisse descrever detalhadamente a estrutura da consciência é, desde o início, de ordem epistemológica.

No que diz respeito a Freud, o caminho percorrido se constituiu por vias um tanto quanto diferentes daquelas traçadas por Husserl, pois suas preocupações jamais se limitaram ao campo da epistemologia, ainda que suas descobertas tenham promovido reviravoltas nessa direção (Assoun, 1983). Ao contrário, médico de formação, seu interesse era, sobretudo, clínico, de modo que, para ele, a psicanálise não é responsável por criar visões de mundo (Weltanschauung), entendidas como uma "construção intelectual que, a partir de uma hipótese geral, soluciona de forma unitária todos os problemas de nossa existência, na qual, portanto, nenhuma questão fica aberta, e tudo que nos concerne tem seu lugar definido" (Freud, 1933/2010a, p. 322), tal como fazem a filosofia, religião ou alguns sistemas políticos, mas sim se insere na visão de mundo científica, na medida em que busca investigar a esfera psíquica a partir dos pressupostos e métodos das ciências naturais. Nesse sentido, as investigações de Freud foram realizadas mediante observações de seus pacientes, seus relatos e sintomas, o que lhe conferiu a oportunidade de ter contato com um amplo material de análise e, a partir dele, fundar um campo de saber totalmente novo e com uma estrutura teórico-conceitual própria. Era este empirismo, aliás, que fez com Freud situasse a metapsicologia entre as ciências naturais, uma vez que todos os seus postulados não deveriam ser meras conjecturas, mas sim se fundamentarem nas experiências diárias com os pacientes. Desse modo, ainda que a posição do autor sempre tenha sido a de situar o campo de conhecimento psicanalítico e sua especificidade no interior da visão científica, não se pode deixar de destacar que a psicanálise, com suas considerações metapsicológicas, instituiu configurações epistemológicas e ontológicas próprias, tendo constituído, dessa forma, também seus próprios objetos de estudo e seu método peculiar (Birman, 1991; 
Campos, 2013).

Para Garcia-Roza (1985/2016), o que faz com que a psicanálise não possa ser reduzida a qualquer outra área de saber existente é o conceito de inconsciente, pois, ao apresentá-lo, Freud não somente rompe com uma longa tradição que associava psicologia à filosofia da consciência, mas também delimita a especificidade da psicanálise em relação a esses dois campos de estudo, colocando o status do psiquismo em outra dimensão, a qual se situa em um lugar muito distante daquele assumido por Husserl em seu projeto fenomenológico. Desse modo, se para este a experiência consciente tinha um alto grau de evidência e poderia ser considerada o fundamento de outras formas de conhecimento, para o psicanalista, o aparelho psíquico e as experiências relatadas estão muito distantes de serem transparentes. Não por acaso, é justamente o conceito de inconsciente o ponto de maior discordância entre a tradição fenomenológica e a psicanalítica.

Tal discordância, todavia, não se faz presente no que concerne ao método analítico desenvolvido por Freud, o qual tem como regras fundamentais a associação-livre e a interpretação dos sentidos inconscientes, a fim de que estes se tornem acessíveis à consciência. Essa dimensão do método psicanalítico é, por sua vez, o que faz com que alguns autores apresentem a psicanálise como uma ciência híbrida, situada em um lugar fronteiriço entre as ciências da natureza e as ciências humanas (Ricoeur, 1965; Figueiredo, 1991). É também o método clínico que atrairá o interesse e atenção dos psiquiatras da tradição fenomenológica, os quais passam a questionar as bases naturais nas quais a psicanálise se assenta e, ao mesmo tempo, buscam fundamentá-la em outro chão epistêmico mais compatível com a própria descoberta freudiana de que os sintomas, sonhos e relatos possuem um sentido latente velado (Assoun, 1983).

\section{Heidegger e a noção de Dasein: onde está o homem na metapsicologia?}

"O conceito de Dasein tornou-se [...] o incontornável da psiquiatria" (Jonckheere, 2008, p. 87 [grifos do autor]). Esta afirmação, colocada pelo autor citado ao referir-se à grande influência que o pensamento heideggeriano exerceu na psiquiatria e psicologia, evidencia algo que atualmente não é novidade, a saber, que a referência ao Dasein heideggeriano é lugar-comum entre os saberes $p s i$. Todavia, vale ressaltar que a opção do filósofo por chamar o homem de Dasein deve-se a uma escolha que, para ser 
compreendida em todo seu potencial crítico, não tem como ser tomada fora do horizonte dessa obra.

Discípulo de Husserl, Martin Heidegger (1889-1976) não se limitou a reproduzir os postulados de seu professor e seguiu um caminho de maior independência, o que o conduziu a desenvolver sua própria fenomenologia, operando um deslocamento em relação ao projeto husserliano, e retirando, assim, a fenomenologia de um campo metodológico e epistemológico, para apresentá-la como uma ontologia fundada na analítica existencial. Uma das consequências deste gesto heideggeriano é, segundo Siewert (2012), o abandono das discussões sobre a consciência, para voltar-se à descrição do modo de ser do Dasein, o que pode ser entendido como uma tentativa radical de abandonar o último elo que unia a fenomenologia husserliana à tradição moderna.

Em Ser e Tempo, Heidegger (1927/2012) parte do diagnóstico de que desde Platão, a principal questão da filosofia, a saber, aquela acerca do sentido do ser, caiu no esquecimento. A partir desta constatação, ele considera a necessidade de elaborar o que denominou de ontologia fundamental, isto é, uma ontologia que visasse responder não "o que é o ser?”, mas sim, “como é possível existir a pergunta pelo sentido do ser?”. Tal pergunta, que tem o intuito de voltar às raízes de toda e qualquer ontologia, será a mola propulsora que o conduz à concepção de Dasein, pois entende que este é o único ente que tem a possibilidade de questionar o ser e compreendê-lo. Assim, o projeto da obra em questão tem como fim trazer à luz o modo de ser do Dasein, isto é, explicitar a sua constituição ontológica, com vistas a esclarecer o sentido do ser em geral.

O emprego do termo Dasein nos textos heideggerianos aponta para uma transformação no modo de se conceber o ser do homem, uma vez que não mais o toma sob a ótica do sujeito moderno cartesiano encapsulado em si mesmo, nem como um ente portador de determinações apriorísticas, mas sim como um projeto ek-sistente, desprovido de qualquer fundamentação última e que, por isso, na medida em que existe, coloca em jogo o seu próprio ser. Quando, ao falar sobre a noção de existência em Ser e Tempo, Heidegger (1927/2012) apresenta o Dasein como um ente que traz em seu ser a tarefa de ser, ele está estabelecendo uma diferenciação entre a noção de existência com a qual trabalha, Existenz, daquela que anteriormente era utilizada pela tradição filosófica e a qual ele designa como subsistência (Vorhandenheit). Isso quer dizer que enquanto a tradição procurou conceituar o homem, entendendo sua essência como subsistência e, portanto, como algo pronto e passível de uma definição imutável universal, o autor apresenta o ser 
do Dasein como existência, o que significa que o que está em questão não é apreendê-lo mediante alguma definição em termos de propriedades ou categorias. Ao contrário, diferente dos demais entes, o ser do Dasein deve ser conquistado a cada vez em seu próprio modo de ser. Sendo um ek-sistente e desprovido de fundamento próprio, o Dasein, inicialmente, apenas pode encontrar determinações e sentidos no mundo, rede significativa em meio a qual ele se vê jogado desde o instante em que nasce e que traz consigo as diretrizes em virtude das quais ele orientará o seu existir. A estrutura ser-nomundo (In-der-Welt-sein) é apresentada, então, como uma estrutura fundamental a priori do Dasein, sendo a partir dela que Heidegger (1927/2012) apresenta o conhecimento não mais como uma faculdade intelectiva de um sujeito substancial, mas sim como um modo constitutivo de ser do Dasein.

Embora as considerações aqui apresentadas estejam muito longe de esgotarem as discussões que Ser e Tempo engendra, é importante destacar a concepção heideggeriana do ser do homem, a qual não parte de definições tradicionais e de áreas de conhecimentos já estabelecidas, como a biologia, a antropologia ou a psicologia, por exemplo, mas sim procura resgatar a especificidade humana. Não por acaso, as ideias de Heidegger exerceram grande influência na psiquiatria e psicologia, tendo sido ponto de partida para as críticas endereçadas à concepção de homem com a qual psicanálise freudiana trabalha.

Apesar de Ser e Tempo ter sido o ponto de partida para os psiquiatras desenvolvedores da daseinsanálise, é nos "Seminários de Zollikon", nome dado ao conjunto de preleções ministradas por Heidegger durante dez anos (1959-1969) a Boss, alunos e psiquiatras interessados em melhor conhecer as ideias do filósofo, que o filósofo apresenta, ainda que de modo fragmentado e sem grandes aprofundamentos, algumas considerações aos postulados freudianos e à psiquiatria. Nesses seminários, Heidegger profere uma frase que parece sintetizar o seu questionamento em relação à teorização freudiana. Diz ele, "Será que em toda a construção freudiana da teoria da libido o homem está mesmo aí?" (Heidegger, 1987/2001, p. 192). Essa pergunta expressa o cerne da problemática colocada em jogo pelo filósofo no que diz respeito à sua leitura da psicanálise, a saber, de que ela, por ser debitária da ciência moderna, explica o homem do ponto de vista das ciências da natureza, tomando-o como um objeto e negligenciando, assim, aquilo que o constitui de modo mais essencial, a saber, sua relação com o ser.

As tentativas de explicação de fenômenos humanos a partir de pulsões têm o Revista Natureza Humana, São Paulo, v.22, n.1, pp.123-152, 2020. 
caráter metódico de uma ciência, cuja matéria não é o homem, mas sim a mecânica. Por isso, é fundamentalmente discutível se um método tão determinado por uma objetividade não-humana pode mesmo ser apropriado para afirmar o que quer que seja sobre o homem qua homem. (Heidegger, 1987/2001, p. 192)

Essa impossibilidade de alcançar o homem se dá, sobretudo, porque nesse projeto de ciência ele somente poder ser visto e estudado como um ente natural que, para ser conhecido, deve ser explicado a partir de causas, as quais, no caso da psicanálise, seriam causas psíquicas inconscientes. Seria isso, segundo Heidegger (1987/2001), que Freud faz quando se utiliza de conceitos como pulsão e sistematiza a vida humana em um aparato psíquico. Isto é, Freud pensaria que a causa dos nossos atos estaria em algo como a pulsão, ou na dimensão do inconsciente, desconsiderando, portanto, que somos uma abertura (Erschlossenheit). Assim, como apresenta Ribeiro (2014), Freud introduz o conceito de inconsciente com o propósito de encontrar a causa daqueles atos psíquicos que, até então, não eram passíveis de explicações quando se equiparava o psiquismo apenas à consciência, tais como os lapsos de memória, por exemplo. Desse modo, o que parece estar em questão para Freud é que nada, no que concerne à vida psíquica, pode estar sem explicação ou existir sem que haja uma causa, de tal modo que, se a explicação não pode ser atribuída aos processos conscientes, então, é preciso lançar mão de uma outra instância, hipotética e não diretamente acessível, capaz de dar conta de tudo aquilo que escapa à consciência.

Segundo Heidegger (1987/2001), é essa necessidade freudiana que faz com que ele tenha que postular leis para o funcionamento do psiquismo, tomando por base os preceitos das ciências naturais, como a física. Considerando as afirmações do próprio pai da psicanálise, não parece que ele negaria o lugar epistemológico que o filósofo alemão lhe coloca, uma vez que não são poucos os textos em que Freud, explicitamente, insiste que seu propósito é alocar a psicanálise no rol das ciências da natureza. Aliás, como adverte Assoun (1983), para Freud não há outra ciência senão a ciência natural. Daí porque Binswanger e Boss, ao seguirem os passos da crítica de Heidegger, tentaram oferecer outro fundamento à psicanálise, que não o naturalista.

\section{Crítica da Psiquiatria fenomenológica por Binswanger e Boss}

Na esteira das ideias de Husserl e Heidegger, Binswanger (1881-1966), formado 
em psicanálise, amigo pessoal de Freud e seu interlocutor desde 1907, pode ser considerado como aquele com quem se iniciam os primeiros diálogos entre a psiquiatria fenomenológica e a psicanálise, bem como o desenvolvimento de um modo completamente novo de se pensar a psiquiatria que viria a ser nomeado posteriormente como daseinsanálise (Jonckheere, 2008). Mais do que isso, como afirmam Dastur e Cabestan, Binswanger "ocupa na história entrecruzada da psiquiatria, da psicanálise e da fenomenologia um lugar sob qualquer ponto de vista privilegiado, que confere à sua crítica ao freudismo um valor completamente particular" (2015, p. 196).

Embora Binswanger tenha mantido uma amizade profunda com Freud durante trinta anos, os laços íntimos que os uniam não o impediram de confrontar as ideias daquele por quem nutriu durante toda a vida uma admiração inquestionável. Grande parte desse impulso inicial adveio de sua leitura da obra de Husserl, a qual o inspirou a apresentar a fenomenologia como uma ciência eidética, capaz não só de permitir a refundação das bases da psicologia, psiquiatria e psicopatologia, como também de retirálas da posição naturalista em que estavam inseridas (Binswanger, 1923/2013a). Foi imerso nesse projeto de refundação das ciências " $p s i$ " que ele, apesar de defender a cientificidade da psicanálise e elogiar o pioneirismo de Freud ao fundar uma hermenêutica baseada na experiência empírica, foi conduzido em direção à necessidade, tanto de rever a técnica psicanalítica, como também e, sobretudo, de assumir uma postura metodológica e epistemológica diante dos textos freudianos (Binswanger, 1926/2013b).

Na ocasião, o inconsciente, principal conceito da psicanálise, não passou ileso das análises críticas binswangerianas, de tal forma que, se por um lado, a descoberta freudiana de que os atos psíquicos possuem um sentido chamava positivamente a atenção do psiquiatra, por outro, a concepção metapsicológica, que concebe o inconsciente como uma instância hipotética, fruto de uma construção científica baseada em observações empíricas, era algo a ser questionado e revisto. Segundo Pita e Moreira (2013), essa postura de Binswanger é definitivamente assumida após o contato com a obra Ser e Tempo de Heidegger, cujas ideias marcam de modo significativo os seus passos na psiquiatria e seu projeto de refundação das bases dessa ciência, despertando-o para alguns dos limites presentes nas considerações de Freud. Um dos textos centrais para essa discussão é o texto "A concepção freudiana do homem à luz da antropologia", em que o autor opõe a visão do homem como Dasein em relação ao homo natura freudiano (Binswanger, 1936/1970). O homo natura seria não um homem real, mas um homem 
ideal, fruto de uma exigência da pesquisa naturalista e que, por esse motivo, não é outra coisa senão "uma construção científica, possível somente sobre o terreno de uma destruição da experiência total do homem pelo homem, isto é, da experiência antropológica" (Binswanger, 1936/1970, p. 221).

Assim, a grande questão colocada por Binswanger é que a ciência da natureza sobre a qual se funda a psicanálise freudiana não dá conta de abarcar a totalidade da experiência humana e sua historicidade, pois, na medida em que toma o homem como um objeto, ela deixa em segundo plano aquilo que é sua grande especificidade, a saber, o trabalho com as questões de sentido. Por essa razão, a sua proposta de nunca foi a de um abandono completo da psicanálise, mas sim promover uma ultrapassagem dos pressupostos naturalistas desta (Assoun, 1983).

A despeito das críticas ao naturalismo freudiano, Binswanger (1957/2013c), em sua conferência em comemoração aos cem anos do nascimento de Freud, avalia que em seu percurso até a psicanálise houve uma etapa final, em que ele constata que sua crítica antropológica ao homo natura de Freud não poderia ser a última palavra dada neste diálogo com a psicanálise. Isso porque, para ele, se por um lado os textos freudianos apresentam uma concepção naturalista de natureza, por outro, eles também trazem uma visão de natureza que não se reduz a essa das ciências naturais. Tecendo comparações com a ideia de natureza em Goethe, Binswanger (1957/2013c) defende que com a ideia de pulsão Freud também ultrapassa a concepção do ser como natureza no sentido cientifico-natural em direção de uma concepção a partir da qual a natureza é tomada como um ser mítico, em toda sua grandiosidade, intangibilidade, indeterminação e mistério. Por essa razão, acaba por concluir que a verdade da psicanálise não deve ser buscada nas ciências modernas, mas sim "ampliada e aprofundada por meio de uma meditação ontológica, uma meditação sobre a compreensão freudiana do ser como natureza" (Binswanger, 1957/2013c, p. 79).

Com esse gesto, Binswanger parece pagar sua dívida para com Freud, o que não faz que tal pagamento seja recebido sem questionamentos por parte dos críticos. Assim, se é verdade que até o final de sua vida ele tentou mostrar-se fiel à técnica psicanalítica, procurando salvá-la a partir de outras bases epistemológicas e ontológicas, por outro, Dastur e Cabestan (2015) consideram que essa proximidade dele com a psicanálise parece reduzir-se a uma ligação apenas de amizade com Freud, uma vez que no momento em que Binswanger se aproximou da fenomenologia, ele acabou se desviando 
irremediavelmente do pensamento psicanalítico que tanto o influenciou em seus anos de formação.

Outra figura importante neste cenário de diálogo entre a tradição fenomenológica e a psicanálise foi Medard Boss (1903-1990), psiquiatra também suíço, influenciado e estimulado diretamente pelos trabalhos de Binswanger. A propósito, é preciso frisar, o caminho de ambos foi muito semelhante, uma vez que, assim como Binswanger, Boss também teve formação em psicanálise, estudou com Freud, permaneceu membro da Sociedade Suíça de Psicanálise até o fim da vida e rapidamente se convenceu das fortes implicações que a obra Ser e Tempo traria para a psiquiatria (Holzhey-Kunz, 2018). Todavia, diferente do primeiro, que teve suas ideias duramente criticadas por Heidegger, Boss tornou-se amigo pessoal do filósofo e, inclusive, organizou junto a este os famosos "Seminários de Zollikon". Apesar desses encontros terem influenciado toda a trajetória de Boss a partir de então, antes mesmo da realização destes seminários, ele se propõe a interrogar a psicanálise freudiana à luz da analítica existencial, com o objetivo de investigar se psicanálise e daseinsanálise teriam algo em comum. Essa forma de aproximação fica evidente já nas primeiras páginas da obra:

\begin{abstract}
A semelhança entre os termos psicanálise e daseinsanálise levou à impressão generalizada de que eles se referem a escolas psiquiátricas-psicoterapêuticas concorrentes. Ambos, diz-se, modelam seus procedimentos em certas análises químicas, na medida em que visam dissolver o homem em suas partes componentes. Alega-se que a única outra diferença entre psicanálise e daseinsanálise é que o primeiro chama seu ponto de partida de "psique", enquanto o último chama o mesmo "Dasein" ou "existência" [...] Assim, há ainda mais razão para se determinar - através de uma cuidadosa investigação de suas origens, suas essências e seus respectivos impactos práticos sobre psiquiatria e psicoterapia - se há qualquer conexão entre os dois. (Boss, 1963/1982, p. 2, tradução nossa)
\end{abstract}

Ao analisar essa tentativa de aproximação, Holzhey-Kunz (2018) ressalta que o intuito de Boss ao realizar esta tarefa não foi denunciar a psicanálise ou mesmo condenála. Ao contrário, o que Boss buscou de modo rigoroso foi estabelecer um diálogo frutífero entre a psicanálise e sua própria prática, na medida em que percebeu na descoberta freudiana de que os sintomas têm um sentido e em seu método de tratamento, descrições importantes sobre como o médico ou o analista poderiam cuidar de seus pacientes. Para Boss, aliás, a daseinsanálise seria uma práxis psicanalítica, porém purificada dos "erros teóricos de Freud" (Holzhey-Kunz, 2018, p. 30). Por outro lado, ele teceu inúmeras 
críticas à metapsicologia freudiana e a todo seu conjunto de pressupostos teóricos, pois entendia que nestes aspectos a psicanálise ainda era debitária da tradição metafísica moderna, bem como do naturalismo:

\begin{abstract}
Para evitar confusões desnecessárias, contudo, pensamos que é prudente distinguir entre dois assuntos completamente diferentes, ambos chamados "psicanálise". Por um lado, e este primeiramente, a psicanálise denota um método específico de tratamento médico, com sua própria - pensamento não refletido compreensão tácita do homem; por outro lado, o termo refere-se a teoria psicológica derivada secundariamente do método de tratamento. Os dois modos de compreensão do homem inerentes à terapia psicanalítica e à teoria psicanalítica diferem tanto uma da outra que, às vezes, resultam em claras contradições, especialmente no que diz respeito às duas características mais importantes. (Boss, 1963/1982, p. 58, tradução nossa)
\end{abstract}

Com esse argumento, o autor esclarece que o daseinsanalista assume posições bem distintas diante da psicanálise, a saber, rejeita sua tendência científica de criar pressupostos e conceitos especulativos aos fenômenos observados na prática clínica, ao mesmo tempo que elogia a prática analítica freudiana, em particular, sua descoberta de que os atos psíquicos possuem um sentido. Assim, caberia à daseinsanálise voltar a Freud, não para negá-lo, mas para restaurar "o significado e o conteúdo originais das observações reais, imediatas, concretas e mais brilhantes de Freud, às quais seus conceitos teóricos apontam de posições distantes e abstratas" (Boss, 1963/1982, p. 59, tradução nossa). Para Dastur e Cabestan (2015), no entanto, essa distinção sobre a qual Boss se apoia para endossar o diálogo entre daseinsanálise e psicanálise parece artificial, uma vez que há de se questionar a real possibilidade de se conceber a atuação clínica de Freud de modo desarticulado com seus pressupostos teóricos.

Alheio a esse tipo de questionamento, o autor prosseguiu em seu projeto de modo a questionar a estrutura especulativa do corpo teórico freudiano, a qual, segundo ele, operaria no interior de um paradigma causal que, além de tudo, concebe o homem como uma máquina e dota-o com uma instância inconsciente. Essa concepção, de acordo com o psiquiatra, além de ser incompatível com a existência humana, também não teria nenhuma razão: "por isso, o desejo para a descoberta das conexões significativas nunca podem ser um motivo válido para a assunção de um inconsciente que estaria para além da experiência imediata" (Boss, 1963/1982, p. 92, tradução nossa). Isso porque ele entende que na medida em que Freud apresenta o caráter necessário do inconsciente sob 
a justificativa de que a consciência apresenta atos psíquicos lacunares para os quais não há explicação, o psicanalista parte do pressuposto de que tudo tem que ser explicado mediante um nexo causal que não aceita que nada escape às explicações. Desse modo, como se pode observar, as críticas de Boss (1963/1982) à psicanálise revelam consonâncias com aquelas feitas por Heidegger (1987/2001).

Assim, após percorrer, ainda que de modo panorâmico, as duas mais conhecidas tentativas de aproximações entre a tradição psiquiátrica fenomenológica, em particular aquela influenciada por Ser e Tempo, com a tradição psicanalítica freudiana, não há como deixar de observar que as discussões empreendidas por Binswanger e Boss caminham no sentido de uma acusação ao desvio naturalizante da psicanálise de Freud, opondo-se, sobretudo, em relação ao conceito de inconsciente e de pulsão, objetos fundamentais da psicanálise. Tal posicionamento representa, em grande medida, a tendência que esta tradição seguiu em suas críticas dirigidas à psicanálise, que consistiu em atacar a suposta doença incurável que acometeu a metapsicologia freudiana, a saber, sua herança materialista, mecanicista, determinista e naturalista. Assim, o principal ponto de impasse pelo qual a psicanálise é acusada refere-se à incompatibilidade que há em assumir um modelo energético para explicar o funcionamento do psiquismo e, ao mesmo tempo, utilizar-se de um método que busca traduzir os sentidos dos fenômenos apresentados no contexto clínico. É partindo dessa crítica, portanto, que tanto Binswanger quanto Boss buscaram, na tradição fenomenológica, um novo fundamento epistemológico para a psicanálise (Assoun, 1983).

\section{Freud e Heidegger: a atualidade de um debate?}

Depois de percorrido o caminho de diálogo entre a tradição fenomenológica daseinsanalítica e a tradição psicanalítica, é oportuno agora estabelecer um panorama geral de como esse diálogo vem sendo levado a cabo nas últimas décadas, de modo que este tópico se centrará nos trabalhos que buscam apresentar alguma espécie de interlocução entre Heidegger e Freud, não apenas no campo da psiquiatria ou da psicologia, como também na filosofia.

Como foi possível constatar até o presente momento, a história de diálogo entre a psiquiatria fenomenológica germânica e a psicanálise, inaugurada por Binswanger e Boss, caracteriza-se por uma intolerância em relação à noção de inconsciente, bem como à 
explicação dos fenômenos psíquicos pela via das ciências naturais. Apesar do esforço de ambos nessa direção de refundação da psicanálise em bases existenciais, Loparic (2001; 2002), ao analisar as objeções que o próprio Heidegger dirigiu às ideias centrais de Binswanger em relação ao uso que este fez das noções de Dasein e ser-no-mundo na elaboração da daseinsanálise psiquiátrica, bem como, ao avaliar se Boss, mesmo acompanhado de perto por Heidegger, conseguiu superar as críticas recebidas pelo primeiro, questiona se ambos fracassaram em suas tentativas de criar uma prática psicoterapêutica heideggeriana e se valeria à pena ainda insistir numa linha de pesquisa que segue essa direção. O autor defende que sim, por entender que o problema não está na impossibilidade da criação de uma ciência fundada na analítica existencial de Heidegger, mas sim no modo como este projeto foi levado adiante por Binswanger e Boss, que acabaram por perder de vista que a daseinsanálise, por lidar com o sofrimento humano, precisa ser uma ciência ôntica. Nesse sentido, o autor ainda acrescenta que a própria psicanálise, mais precisamente, aquela desenvolvida por Donald Winnicott (1896-1971), cumpre, involuntariamente, com a tarefa colocada pela daseinsanálise de construir uma psicanálise não assentada na visão de homem naturalista, defendendo, assim, que a aproximação das ideias de Heidegger com as ciências humanas ainda pode ser promissora.

Dentro ainda dessa posição inicial que critica e tenta corrigir a psicanálise pela via da tradição fenomenológica, mais recentemente, o filósofo e também psicanalista Pearl (2013a) procura elucidar e repensar alguns fundamentos e conceitos centrais da psicanálise freudiana à luz da noção heideggeriana de temporalidade. Embora se trate de uma tentativa filosófica, o autor não deixa de destacar que a escolha pela noção de temporalidade se dá por essa ser essencial também na própria teoria psicanalítica, bem como por sua função no encontro terapêutico, como é o caso da noção de transferência, que implica uma dimensão temporal presente; traz a importância de vivências passadas na história do paciente; e, também, o reconhecimento da existência de fantasias inconscientes e do desejo, ambos, da ordem do futuro. Como o autor mesmo afirma, ele encontra-se na esteira das tentativas de Binswanger e Boss, que buscaram fundamentos ontológicos para alguns conceitos psicanalíticos. Contudo, seu intuito é não repetir o mesmo erro metodológico de ambos, que acabaram por não articular a psicanálise à estrutura ontológica mais fundamental apresentada por Heidegger, a saber, a temporalidade. Além desse livro em que trata da temporalidade, Pearl (2013b) também procura em outro texto fazer uma elucidação ontológica, com base em Heidegger, de 
outro conceito presente na psicanálise, a saber, o narcisismo. No trabalho em questão, o autor retoma a leitura freudiana e lacaniana acerca do estágio do narcisismo, ao reler este conceito a partir da condição constitutiva de abertura do eu ao Outro pela via da temporalidade. Segundo Pearl (2013b), a temporalidade futura já traz em si a alteridade radical que integra o eu e o abre para as suas possibilidades de ser. Nesse sentido, a unidade de si é conquistada não de modo especular, como diz Lacan, mas sim pela unidade temporal concernente a todo Dasein.

Além dos trabalhos que buscam superar o naturalismo da metapsicologia freudiana, há, também, aqueles que se encontram em uma posição intermediária nesse campo de interlocução, uma vez que correspondem a propostas que avançam no caminho de articulação entre essas duas dimensões. Embora o impulso para este tipo de interlocução tenha sua origem entre os franceses, mais especificamente, com MerleauPonty e Ricoeur, e, por isso, seja mais comum de ser estabelecida a partir deles, na atualidade é possível alocar neste grupo intermediário alguns autores, geralmente psicanalistas, que recorrem a Heidegger na tentativa de fazer emergir no próprio corpo teórico e clínico da psicanálise algumas perspectivas que já teriam sido entrevistas por Freud, mas que não tinham como ser apreendidas por completo enquanto o pensamento psicanalítico permanecesse sob o domínio do naturalismo.

Entre estes nomes, vale destacar Figueiredo (1994; 1996a; 1996b; 1999), pesquisador nacional, que redigiu alguns trabalhos nessa direção. Em seus textos, ele se aproxima das reflexões de Heidegger, não para buscar outro fundamento epistemológico para a psicanálise ou negar a origem funcionalista desta, mas sim para ampliar o campo de saber psicanalítico a partir de um tensionamento com a filosofia heideggeriana. Por essa razão, este autor, quando busca uma aproximação com algumas das ideias desse filósofo, sempre faz questão de enfatizar que seu intuito não é fazê-las incidir sobre o corpo teórico da psicanálise de modo a se sobrepor a esta ou a falar sobre esta a partir de Heidegger. Ao contrário, trata-se de "trazer o pensamento de Heidegger para perto das questões que se fazem ou se podem abrir a partir da clínica" (Figueiredo, 1996a, p. 39). Ou seja, as ideias do filósofo viriam ajudar a psicanálise a ver melhor aquilo que ela mesma já trata e não para lhe oferecer outro fundamento epistemológico. Para tanto, o autor privilegia alguns ângulos a partir dos quais acredita que este encontro possa ser efetivado, apoiando-se, sobretudo, nos textos e preleções de Heidegger após a década de 30, no seu período conhecido como viragem, momento caracterizado por um estudo sobre 
a história da verdade do Ser, em que o autor traz à luz a discussão sobre a noção de acontecimento (Ereignis), linguagem e técnica.

Assim, Figueiredo $(1994 ; 1996 a)$ se apoia nas concepções de linguagem de Heidegger para abordar a dinâmica dos enunciados em análise, dando especial destaque para a noção de acontecimento, mais precisamente, de fala acontecimental, isto é, uma fala estranha e não familiar, na qual há a irrupção do inesperado. Além disso, também se aproxima na noção de serenidade (Gelassenheit) formulada por Heidegger, para pensar a postura de reserva e implicação do analista. Para ele, a serenidade, "capacidade de esperar o inesperado, de sustentar-se na abertura do aberto, sem fugir na direção dos entes para neles se apoiar" (Figueiredo \& Coelho Junior, 2008, p. 50), seria semelhante à atitude neutra e firme da atenção/desatenção flutuante do analista a tudo o que é dito pelo analisando. De acordo com o autor, seria essa posição de reserva do analista que manteria aberto o espaço para que o analisando pudesse ter uma experiência com a linguagem, de modo a ser transformado por ela.

Além de pensar a postura do analista com o auxílio de Heidegger, Figueiredo (1999) também procura aprofundar a temática da angústia, tão discutida por Freud ao longo de seu percurso de elaboração e amadurecimento da psicanálise. Para tanto, o autor procura analisar em que medida e em quais aspectos, a introdução da noção de angústia originária apresentada por Freud após a década de 1920 extrapola e rompe com um posicionamento estritamente funcional da teoria freudiana. Um dos pontos destacados pelo autor diz respeito à temporalidade dessa modalidade de angústia. Isso porque, ela não teria como se constituir como uma vivência no momento em que ocorre, devido a ainda não existir um eu formado na ocasião do nascimento, o que faz com que as vivências de angústia posteriores sejam repetições da situação originária, a qual apenas deixa traços que apelam por receberem sentido. Ou seja, seria apenas num momento posterior, após a constituição de um eu, que a primeira angústia e os traços por ela deixados poderiam ser convertidos em uma experiência vivida. Com isso, o autor compreende que a angústia originária é atemporal, uma vez que segue existindo mesmo quando outros tipos de angústia se desenvolvem e, também, por receber seu sentido somente a posteriori, algo que, além de romper com a matriz funcionalista e organicista que trabalha com uma concepção desenvolvimentista de tempo, também possibilita pensar na existência de uma dimensão "que diz respeito à condição humana e ao modo especial de vir a ser que nos caracteriza" (Figueiredo, 1999, p. 61). É para iluminar essa problemática, que ele recorre 
à compreensão de angústia formulada por Heidegger em Ser e Tempo.

Apesar desses possíveis encontros, Figueiredo $(1994 ; 1999)$ não deixa de defender a psicanálise freudiana das críticas daqueles que a acusam de naturalista e que, por este mesmo motivo, a consideram arbitrária em seus aspectos teóricos. O autor argumenta, ainda, que a psicanálise aponta para a existência de algo que é da ordem do "não-humano" no homem e que essa dimensão precisa ser acolhida, independente do léxico psicanalítico que venha a ser utilizado. O que não se pode fazer, afirma o autor, é negar o que é específico da psicanálise.

Em um movimento semelhante ao realizado por Figueiredo, outro autor que também mantém diálogos com a fenomenologia heideggeriana em território nacional é Rocha (2000; 2004). O autor considera que as concepções heideggerianas sobre o Dasein e sobre a angústia podem elucidar em certa medida a condição de desamparo e o afeto da angústia enunciados pelo corpo teórico psicanalítico freudiano. Para tanto, elege a noção de Realangst (angústia real) para apresentar sua linha argumentativa de que na psicanálise é possível encontrar a presença de uma dimensão existencial da angústia. Em resumo, o autor defende que, ao indicar que o perigo externo é o perigo da castração, Freud dá indícios de que a Realangst se situa em uma realidade que não é empírica, mas sim originária e estruturante, como um registro do inominável, algo semelhante à angústia ontológica heideggeriana:

Na medida em que, também para Heidegger, a angústia não é uma realidade objetiva que se pode determinar; na medida em que ela tem uma dimensão originária; na medida em que ela é uma disposição constitutiva do ser humano jogado no mundo e destinado à morte; na medida em que Heidegger, articulando a angústia com a experiência do nada e do sentir-se estranho na própria casa, correlaciona a angústia com o desamparo, eu, pessoalmente, tenho a impressão que, em campos totalmente distintos descobriram coisas muito próximas sobre o enigma da angústia. E se a pulsão de morte tivesse sido mais lembrada na reformulação freudiana de sua teoria da angústia, por certo esta analogia, que compara elementos que, na sua diferença, têm algo semelhante, seria ainda maior. (Rocha, 2000, p. 156)

Contudo, embora o autor avente a possibilidade de aproximação entre a angústia descrita por Heidegger e a angústia originária (Urangst) do nascimento apresentada por Freud, esta articulação não é desenvolvida e resume-se a algumas notas que precisariam ser melhor exploradas. O mesmo acontece com Figueiredo (1999), quando este autor recorre a Heidegger para melhor pensar acerca dos limites do funcionalismo na 
compreensão da angústia originária.

Rocha (2004) ainda procura, a partir de sua leitura de Ser e Tempo, subsídios para pensar a questão da temporalidade na psicanálise freudiana. Isso porque, acredita que a noção tradicional de tempo linear na qual Freud se baseava para sustentar sua hipótese de que o psiquismo pode ressignificar experiências antigas na análise, não era suficiente para explicar e fundamentar seus próprios argumentos em torno desta questão. Desse modo, o autor entende que a concepção heideggeriana de que o tempo não é uma sucessão de instantes, mas sim uma interligação entre passado, presente e futuro, é mais compatível com a proposta freudiana de que até mesmo vivências ocorridas na infância podem adquirir novos sentidos. A ênfase dada por Rocha (2004) recai sobre o termo Gewesenheit, que corresponde a uma força instaurada no passado, que se mantém viva e atuante no presente, abrindo espaço não apenas para a repetição do que foi, mas também para a restauração e renovação daquilo que está sendo repetido.

Já o norte-americano Stolorow possui uma série de artigos e livros (2006; 2007; 2011; 2015) em que busca fazer uma aproximação não apenas entre Heidegger e Freud, como também, entre Heidegger e outros psicanalistas contemporâneos por meio do que conceitua como psicanálise fenomenológica. Um dos eixos centrais de suas discussões se dá em torno da noção de trauma e de como o contexto psicoterapêutico pode se beneficiar dessas discussões. Para tanto, retoma a análise heideggeriana de que o existir se sustenta e encontra sentido e familiaridade no mundo, sendo que experiências traumáticas podem revelar a estranheza e esvaziamento do existir e levar a uma espécie de desintegração da vida cotidiana. Nos trabalhos citados, o autor procura defender que, assim como a finitude e a vulnerabilidade constituem a existência humana de modo fundamental, também a coexistência e a capacidade de formar laços afetivos fazem parte dessa constituição. Com isso, ele procura trazer as contribuições de Heidegger e da fenomenologia para o interior da psicanálise, ampliando-a em direção de uma dimensão ética do existir humano, na medida em que procura resgatar sua fragilidade e ver nela a possibilidade de envolvimento com o outro. Vale destacar, também, que embora Stolorow parta de Freud, seus trabalhos não se restringem à psicanálise freudiana, mas avançam em direção à constituição de um caminho próprio de pensamento que procura desvencilhar a psicanálise de sua herança intrapsíquica, para estudar os mesmos fenômenos com os quais ela se ocupa sob uma perspectiva da experiência contextual, relacional e intersubjetiva, que encontra fundamentação não só em Heidegger, como também na hermenêutica 
filosófica de Gadamer e na filosofia existencialista. Com isso, a psicanálise desenvolvida por Stolorow e seu grupo acaba por apresentar uma outra estrutura de relação analistapaciente, que se sustentará não na interpretação dos fenômenos psíquicos, mas na construção dialógica de sentidos.

Também com o intuito de apresentar possíveis reflexões que esse diálogo entre Freud e Heidegger podem oferecer para se pensar a relação terapêutica e intervenções clínicas, Acosta e Andrews (2012) procuram discutir de que maneira a desconstrução heideggeriana de noções psicológicas como as de subjetividade, intersubjetividade e empatia, amplamente debatidos pela filosofia fenomenológica de Husserl, Sartre e Stein para abordar a possibilidade de apreensão da experiência do outro, são profícuas para iluminar o conceito psicanalítico clássico de atenção uniformemente flutuante. Isso porque, sendo uma das regras fundamentais que orienta a atitude do analista, a atenção uniformemente flutuante é caracterizada, já na definição freudiana, por ser uma atitude não reflexiva e não sustentada pela dinâmica da consciência. Trata-se de uma atitude em que o analista deixa seu inconsciente ser levado pela fala do paciente e por aquilo que ela lhe desperta de modo imediato, antes mesmo que possa pensar sobre ela ou analisá-la. A ele cabe a tarefa de uma escuta que envolve, ao mesmo tempo, a passividade e a espera, bem como a atividade de estar sempre aberto e disponível ao que pode ser manifesto. Segundo os autores, a posição de Heidegger sobre o estar-no-mundo de modo préreflexivo e hermenêutico, na medida em que supera a dicotomia entre sujeito e objeto, seria mais adequada para se pensar como é possível haver essa experiência do analista na relação com o paciente, e ainda mais compatível com o que o próprio Freud quis apresentar sobre a dinâmica e natureza desta relação.

$\mathrm{Na}$ daseinsanálise, um trabalho mais recente nessa direção é o da pesquisadora suíça, Holzhey-Kunz (2018), no qual a autora reconhece o débito da daseinsanálise para com as ideias de Freud. Para ela, algo essencial descoberto pela psicanálise é o fato de que o sofrimento tem um sentido velado que precisa ser descoberto. Todavia, enquanto na psicanálise esse velamento é explicado pela existência do inconsciente e do mecanismo de repressão, ela defende que, a partir das considerações de Heidegger, pode-se perceber que o sentido do sofrimento se encontra também na presença de uma verdade ontológica não manifesta explicitamente, da qual as pessoas sempre fogem, mas que sempre ameaça vir à tona e romper com a familiaridade cotidiana do existir. O sofrimento psíquico seria, portanto, um sofrimento com o próprio ser. Ao fazer isso, a principal contribuição desse 
trabalho é a reinserção da daseinsanálise no campo psicanalítico freudiano, sem negar as contribuições de Freud por se inserirem no campo das experiências ônticas, mas ao contrário, procurando introduzir também a dimensão ontológica presente no sofrimento humano. Além disso, a autora mantém, assim como fazem Binswanger e Boss, o método psicanalítico de tratamento, avançando em relação aos trabalhos dos dois psiquiatras na medida em que fundamenta também as regras propostas por Freud para o setting terapêutico em termos ontológicos-existenciais e justifica a manutenção da abstinência, da livre-associação e da atenção uniformemente flutuante na daseinsanálise, argumentando que essas regras abrem espaço para o acesso ao sentido das experiências ontológicas que estão na base do sofrimento psíquico.

Como é possível notar, boa parte dos estudos que aproximam as ideias de Heidegger e Freud o fazem a partir da psicanálise ou da filosofia e, geralmente, com o intuito de, ou ampliar os horizontes da psicanálise, ou oferecer a esta fundamentos epistemológicos mais condizentes com a sua especificidade. Além destes trabalhos, há também aqueles que apresentam estes dois autores juntos, porém com o intuito de reconstruir as críticas que o filósofo ou seus seguidores operam em relação à metapsicologia freudiana, avaliando em que medida elas são ou não pertinentes e, de modo geral, enfatizando apenas os distanciamentos entre ambos. Entre trabalhos dessa natureza, podemos citar Dallmayr (1993); Dastur (1998); Loparic (1999; 2001; 2002); Bühler (2004); Matteo (2005); Owen (2006); Ribeiro (2008; 2014); Barua e Das (2014). No caso desse último estudo, embora as autoras concordem que a psicanálise freudiana possa convergir com a fenomenologia de Husserl e Heidegger no que concerne ao trabalho com os sentidos, essa aproximação apenas seria possível no âmbito da reflexão acerca da prática clínica. Nesse sentido, consideram que no que tange aos objetivos e concepção de homem, as escolas psicanalíticas e fenomenológicas ainda estão muito distantes e têm, entre si, obstáculos de comunicação que são quase intransponíveis.

Já o estudo de pesquisador australiano Fowler (2004), ao mesmo tempo em que procura defender Freud das críticas de que a psicanálise teria seu fundamento reduzido a um mero cartesianismo, apresenta de que modo a teoria freudiana também converge com a concepção ontológica de ser-no-mundo descrita por Heidegger, uma vez que entende que em Freud o psiquismo não é algo estático, essencialista e fechado em si mesmo, mas sim marcado por uma dinâmica pulsional e inconsciente que o movimenta e o torna ativo na construção de sentidos e da realidade. Além disso, o autor entende que, para Freud, 
sobretudo a partir de suas considerações sobre o narcisismo, o Eu passa a ser visto como relacional. Com isso, entende que a psicanálise oferece dados empíricos à descrição fenomenológica de que não há um sujeito autônomo e isolado, mas sim um ser-com. Esse é um dos poucos trabalhos que procura seguir o movimento inverso, isto é, que mostra de que maneira a psicanálise também pode ampliar ou melhor iluminar as reflexões heideggerianas. O mesmo ocorre com a tentativa de Holzhey-Kunz (2018), citada anteriormente, que procura ampliar os horizontes da daseinsanálise à luz do conhecimento psicanalítico.

Seguindo em outra direção, há algumas pesquisas que se constituem como tentativas de encontrar pontos de articulações entre Heidegger e Freud, porém respeitando as divergências e o lugar teórico-epistemológico de ambos. Nessa linha há o trabalho de Svenaeus (2000), que em um artigo publicado na área da saúde, procura demonstrar a possibilidade de pensar fenomenologicamente a essência do adoecimento a partir da noção de estranhamento ou sentir-se estranho. Seu propósito é encontrar uma espécie de característica geral das doenças no conceito de Unheimlichkeit tanto nos trabalhos de Freud como nos de Heidegger, defendendo, para tanto, que a despeito das diferentes visões de mundo que estes autores trabalham, ambos abordam essa dimensão fundamental dos fenômenos humanos e permitem compreender o adoecimento - mental e físico como uma experiência que, por romper com a familiaridade cotidiana, revela a nossa condição latente de sentir-se fora de casa. O estudo de Warsop (2011), por sua vez, embora também discuta o estranhamento na situação de adoecimento do corpo, parte da hipótese de que na doença temos a revelação de nossa própria condição finita, como exemplo, quando se descobre um câncer. Em suas considerações, o autor parte de Heidegger e Freud, pois entende que os dois partilham da ideia de que o estranho é capaz de revelar algo que já sempre esteve presente em nossa vida, mas de que nos encontrávamos alienados.

O estudo realizado por Carel (2006), pesquisadora australiana que abordou as relações existentes entre a morte e a vida nos textos de Freud e Heidegger, é um dos poucos que avança no sentido de promover um diálogo entre estes dois autores para além das críticas heideggerianas sobre a psicanálise apresentadas nos Seminários de Zollikon, e sem recair em uma postura apologética sobre um ou outro acerca do tema abordado em sua pesquisa. Ao contrário, ela defende que há pontos de conexões entre ambos, sobretudo no que diz respeito a alguns dos temas e objetos estudados por eles, mesmo que tal 
proximidade não possa ser admitida no que concerne aos seus métodos, pressupostos e objetivos. No trabalho em questão, ela estuda a morte como elemento central e estruturante da vida, a partir das concepções de pulsão de morte em Freud e ser-para-amorte em Heidegger, tecendo aproximações e distanciamentos entre as propostas dos dois autores, porém com o intuito de que as contribuições de ambos possam fundamentar uma tanatologia, tarefa que ela procura realizar na última parte de seu livro. Carel (2006) afirma que em ambos seria possível encontrar uma visão de morte que não estaria desvinculada ou dicotomizada da vida, mas que, ao contrário, é o que confere sentido a ela. Na análise da obra freudiana, ela parte da pulsão de morte, afirmando que esta e Eros não são forças opostas e nem independentes. Ao contrário, na medida em que enfatiza a dimensão autodestrutiva e a força de aniquilação da pulsão de morte e defende que ela constitui Eros (pulsão de vida), a autora apresenta que a vida psíquica se dá numa luta constante, em que a possibilidade de morte está sempre iminente. Quanto a Heidegger, ela entende que quando o autor fala da morte, ele está se referindo à presença da finitude nas possibilidades da vida, estando, portanto, também no fundamento desta e sempre pronta para se manifestar a partir da experiência da angústia. A principal diferença que ela aponta entre os dois autores é em relação ao que se pode saber sobre a própria finitude, haja vista que, se para Freud, a morte de si não encontra representante psíquico, para Heidegger, o homem, ainda que fuja da morte pela perda de si em meio à dinâmica cotidiana inautêntica, sabe da morte, por ela ser seu poder-ser intransferível e inelutável.

Em suma, é possível dizer que nesses estudos mais atuais citados há um avanço em relação às tradicionais críticas empreendidas pela tradição fenomenológica e existencial às hipóteses naturalistas de Freud. Assim, estudos como os de Figueiredo (1994; 1996; 1999) e Rocha (2000), psicanalistas que buscaram iluminar a psicanálise com a ontologia heideggeriana, aliados aos trabalhos atuais já citados de Carel (2006) e Warsop (2011), abrem a possibilidade de pensar o diálogo entre a tradição fenomenológica germânica e a psicanálise freudiana na atualidade, a partir de outra via que não aquela dos precursores desse empreendimento, os quais, em suas tentativas, centraram seus esforços em eliminar a dimensão biológica e naturalista da psicanálise. Esse movimento de mudança de rumos nas pesquisas é importante por respeitar os dois campos epistemológicos em jogo neste debate, sem negar suas respectivas especificidades.

No que se refere à psicanálise mais diretamente, Freud parece, desde o início de 
suas elaborações teóricas, encontrar-se em um entre epistemológico que foi desconsiderado pela daseinsanálise de Binswanger e Boss. Este espaço no qual ele se situa é exatamente o do limite e da tensão entre o campo do biológico-natural e um campo do sentido que, por transcendê-lo, seria irredutível a este, tal como demonstra Campos (2014). Daí, não por acaso, a concordância entre vários autores acerca da dificuldade que há em situar a psicanálise de modo rígido e consensual em uma matriz epistemológica específica (Ricoeur, 1965; Figueiredo, 1991; Campos, 2013). Naturalmente, esta também não é uma posição consensual, uma vez que tantos outros autores reafirmam o naturalismo freudiano, argumentando que, apesar de a psicanálise trabalhar com interpretações de sentidos, mesmo seu método é objetivo e calcado nas ciências da natureza (Assoun, 1983; Mezan, 2007).

Em todo caso, é no sentido das poucas tentativas de encontrar pontos de articulações entre Heidegger e Freud, respeitando as divergências e o lugar teóricoepistemológico de ambos que, em nossa concepção, na atualidade é possível encontrar um ponto de confluência a partir do qual as obras do filósofo e seus seguidores, e aquelas que se fundam na psicanálise freudiana podem ainda dialogar. O que se observa em trabalhos desta natureza é a busca por um elo comum de discussão, o qual pode ser elucidado com contribuições dos dois campos e sem, contudo, defender que entre eles exista um lugar epistemológico comum, uma vez que a tentativa de operar um apagamento dos traços intransponíveis que os separam já cairia derrotada logo de início.

\section{Considerações finais}

Após ter apresentado de quais maneiras o diálogo entre daseinsanálise e psicanálise tem sido realizado, é oportuno retomar a questão inicial colocada por este trabalho, a saber, se a interlocução entre essas duas escolas ainda tem lugar na atualidade e, se sim, que lugar é este. Como foi possível acompanhar com os trabalhos apresentados, as tentativas de refundar a psicanálise pela via do pensamento heideggeriano e suas ramificações parecem se tratar de empreendimentos que, embora ainda encontrem afiliados, não avançam no sentido de contribuir com as duas áreas em questão, haja vista que giram em torno de uma discussão epistemológica que muitas vezes se assemelha a um ato de exorcização que buscar expulsar o o naturalismo existente nos textos freudianos e em sua metapsicologia. Algo semelhante pode ser dito em relação aos trabalhos que 
retomam a crítica heideggeriana aos pressupostos naturalistas de Freud. Embora se tratem de pesquisas importantes no sentido de elucidarem tais argumentos e de os apresentarem de modo sistemático e rigoroso, protegendo-os, portanto, de reproduções superficiais e apressadas, acabam por restringir as possibilidades de interlocuções que poderiam emergir do choque entre tradições, de fato, tão díspares quanto a ontologia heideggeriana e a psicanálise freudiana. Neste sentido, pensar uma possibilidade de diálogo entre Heidegger e Freud a partir de um lugar que não seja aquele da reconstrução ou explicitação das críticas heideggerianas ao modelo metapsicológico freudiano e que também não busque negar e desconsiderar a especificidade de cada um dos dois campos teóricos em que se situam estes dois autores parece ser o grande desafio aos pesquisadores que, na atualidade, não temem entrar nesse terreno o qual, apesar de há muito ter sido um campo de batalha, hoje tenta levantar uma bandeira de paz. Tal projeto parece viável, desde que não se caia na tentação de defender ou acusar um dos lados dessa história.

\section{Referências}

Acosta, C.L.; Andrews, V.G.H. (2012). Psicoanálisis y fenomenología heideggeriana: la atención parejamente flotante. Praxis. Revista de Psicología, 14(22), 45-64.

Assoun, P.L. (1983). Introdução à epistemologia freudiana. Rio de Janeiro: Imago.

Assoun, P.L. (2009) Freud, la philosophie et les philosophes. Paris: PUF. (Trabalho original publicado em 1976).

Ayouch, T. (2009). Approche de la psychanalyse par la phenomenologie: l'exemple de Merleau-Ponty. Revue de Phenomenologie et de Psychologie Analytique, 7-20.

Ayouch, T. (2012). Maurice Merleau-Ponty et la psychanalyse: la consonance imparfait. Paris: Le bord de l'eau.

Barua, A.; Das, M. (2014). Phenomenology, psychotherapy and the quest for intersubjectivity. Indo-Pacific Journal of Phenomenology, 14(2), 1-11.

Beaulieu, A. (2009). Les démêlés de Merleau-Ponty avec Freud: des pulsions à une psychanalyse de la nature. French Studies, 63(3), 295-307.

Beaune, J.C. (Org.). (1998). Phénoménologie et psychanalyse: étranges relations. Lion: Editions Champ Vallon.

Bernet, R. (2002). Unconscious consciousness in Husserl and Freud. Phenomenology and the cognitive sciences, (1), 327-351.

Binswanger, L. (1970). La conception freudienne de l'homme à la lumière de Revista Natureza Humana, São Paulo, v.22, n.1, pp.123-152, 2020. 
l'anthropologue. In : Binswanger, L. Discours, parcours, et Freud: analyse existencielle, psychiatrie clinique et psychanalyse (R.Lewinter, Trad., pp.201-237). Paris: Editions Gallimard. (Trabalho original publicado em 1936).

Binswanger, L. (2013a). Sobre a fenomenologia. In: Binswanger, L. Sonho e existência: ensaios e conferências I - escritos sobre fenomenologia e psicanálise (M. A. Casanova, Trad., pp.89-138). Rio de Janeiro: Via Verita. (Trabalho original publicado em 1923). Binswanger, L. (2013b). Experiência, compreensão e interpretação na psicanálise. In: Binswanger, L. Sonho e existência: ensaios e conferências I - escritos sobre fenomenologia e psicanálise (M. A. Casanova, Trad., pp.43-62). Rio de Janeiro: Via Verita. (Trabalho original publicado em 1926).

Binswanger, L. (2013c). Meu caminho até Freud. In L. Binswanger. Sonho e existência: ensaios e conferências I - escritos sobre fenomenologia e psicanálise (M. A. Casanova, Trad., pp. 63-88). Rio de Janeiro: Via Verita. (Trabalho original publicado em 1957).

Birman, J. (1991). A constituição da clínica psicanalítica. In: Birman, J. Freud e a interpretação psicanalítica (pp.135-166). Rio de Janeiro: Relume-Dumará.

Boss, M. (1982). Psychoanalysis and Daseinsanalysis (L.B. Lefrebre, Trad.). New York/London: Basic Books Inc. Publishers. (Trabalho original publicado em 1963).

Bühler, K.E. (2004). Existencial analysis and psychoanalysis: especific differencer and personal relationship between Ludwig Binswanger and Sigmund Freud. American Journal of Psychotherapy, 58(1), 34-50.

Cabestan, P. (2010). Être soi-même: approche phénoménologique de l'authenticité et de l'inauthenticité. Natureza Humana, 12(2), 1-15.

Campos, E.B.V. (2013) Considerações sobre o estatuto epistemológico da psicanálise: a teoria das pulsões e a problemática da representação na contemporaneidade. In: Mouammar, C.C.E.; Campos, E.B.V. (Orgs.) Psicanálise e questões da contemporaneidade (pp. 31-46). Curitiba: CRV; São Paulo: Cultura Acadêmica Editora. Campos, E.B.V. (2014). Limites da Representação na Metapsicologia Freudiana. São Paulo: EDUSP.

Carel, H. (2006). Life and death in Freud and Heidegger. Amsterdam: Rodopi.

Dallmayr, F. (1993). Heidegger and Freud. Political Psychology, 14(2), 235-253.

Dastur, F. (1998). Phénoménologie et métapsychologie. In : Beaune, J.C. (Org.). (pp.273284). Phénoménologie et psychanalyse: étranges relations (pp.273-284). Lion: Editions Champ Vallon. 
Dastur, F.; Cabestan, P. (2015). Daseinsanálise: Fenomenologia e Psicanálise. Rio de Janeiro: Via Verita.

Duportail, G.F. (2006). Psychanalyse et phénoménologie: questions et enjeux. Savoirs et clinique, 7(1), 163-174.

Dutra, C.C. (2000). Fenomenologia e (in)consciência: Husserl, Freud e psicoterapia. Revista Estudos de Psicologia, 17(1), 44-54.

Figueiredo, L.C.M. (1991). Matrizes do pensamento psicológico. Petrópolis: Vozes.

Figueiredo, L.C.M. (1994). Escutar, recordar, dizer: encontros heideggerianos com a clínica psicanalítica. São Paulo: Escuta/Educ.

Figueiredo, L.C.M. (1996a). Heidegger e a psicanálise: encontros. Psicanálise e Universidade, (4), 39-51.

Figueiredo, L.C.M. (1996b). Maldiney e Fédida: derivações heideggerianas na direção da psicanálise. Cadernos de subjetividade, (4), 95-108.

Figueiredo, L.C.M. (1999). As províncias da angústia (roteiro de viagem). Revista Latinoamericana de Psicopatologia Fundamental, 2(1), 50-63.

Figueiredo, L.C.M. \& Coelho Junior, N. (2008). Ética e técnica em psicanálise. São Paulo: Escuta, 2008.

Fowler, S.A. (2004). The self-overcoming subject: Freud's challenge to the cartesian ontology. Journal of phenomenological psychology, 35(1), 97-109.

Freud, S. (1996). A interpretação dos sonhos. In: Freud, S. Edição standard brasileira das obras psicológicas completas de Sigmund Freud (J. Salomão, trad., Vols. 4 e 5). Rio de Janeiro: Imago. (Trabalho original publicado em 1900).

Freud, S. (2010a). Acerca de uma visão de mundo. In: Freud, S. Obras completas: O malestar na civilização; Novas conferências introdutórias à psicanálise e outros textos (P. C. de Souza, trad., Vol. 18, pp. 321-354). São Paulo: Companhia das Letras. (Trabalho original publicado em 1933).

Garcia-Roza, L.A. (2016). Freud e o inconsciente. 2ed. Rio de Janeiro: Zahar. (Trabalho original publicado em 1985).

Goto, T.A. (2008). Introdução à Psicologia Fenomenológica: a nova psicologia de Edmund Husserl. São Paulo: Paulus.

Heidegger, M. (2001). Seminários de Zollikon (G. Arnhold \& M. F. A. Prado, Trad.). São Paulo: Educ, Petrópolis: Vozes. (Trabalho original publicado em 1987).

Heidegger, M. (2012). Ser e Tempo. (Trad. Fausto Castilho). Campinas: Editora Unicamp; Revista Natureza Humana, São Paulo, v.22, n.1, pp.123-152, 2020. 
Petrópolis: Editora Vozes, 2012.

Holzhey-Kunz, A. (2018). Daseinsanálise: o olhar filosófico-existencial sobre o sofrimento psíquico e sua terapia. Rio de Janeiro: Via Verita.

Husserl, E. (2012). Investigações Lógicas (P. Alves \& C. Morujão, Trad., Vol. 2, Parte 1). Rio de Janeiro: Forense Universitária. (Trabalho original publicado em 1900) Jonckheere, J. (2008). L' “idée” de la Daseinsanálise. In P. Cabestan, \& F. Dastur (Orgs.). Lectures d'Être et Temps de Martin Heidegger: quatre-vingts ans après (pp. 87-100).. Paris: Le Cercle Herméneutique.

Loparic, Z. (1999a). Heidegger and Winnicott. Natureza humana, 1(1), 103-135.

Loparic, Z. (1999b). É dizível o inconsciente? Natureza humana, 1(2), 323-385.

Loparic, Z. (2001). Além do inconsciente: sobre a desconstrução heideggeriana da psicanálise. Natureza humana, 3(1), 91-140.

Loparic, Z. (2002). Binswanger, leitor de Heidegger: um equívoco produtivo? Natureza humana, 4(2), 383-413.

Loparic, Z. (2007). Origem em Heidegger e Winnicott. Natureza humana, 9(1), 243-273. Lutereau, L. (2011). Acerca de la verdad: Heidegger y Lacan. Fenomenología y Psicoanálisis. Revista Affectio Societatis, 8(14), 2-19.

Lutereau, L.; Kripper, A. (2012). Lo inconsciente em la fenomenologia y el psicoanálisis: la cuestión de la metapsicología. Revista Universitaria de Psicoanalisis, 12, 217-227.

Matteo, V. (2005). Heidegger e Psicanálise: uma conversa em Sicília. Revista de Filosofia, 17(20), 185-198.

Meyer, A.V. (2009). O discurso de Roma: ponto de inflexão da psicanálise. IDE, 32 (49), 170-176.

Mezan, R. (2007). “Que tipo de ciência é, afinal, a psicanálise?”. Natureza Humana, 9(2), 319-359.

Nancy, J-L.; Lacoue-Labarthe, P. (1991). O título da letra. São Paulo: Escuta.

Owen, I.R. (2006). Psychotherapy and Phenomenology: on Freud, Husserl and Heidegger. New York: iUniverse.

Pearl, J. (2013a). A question of time: Freud in the light of Heidegger's temporality. Amsterdam; New York: Rodopi.

Pearl, J. (2013b). The temporal foundation of the self and the other: a phenomenological reading of narcisism. Pastoral Psychology, 62, 533-544.

Pita, J.; Moreira, V. (2013). As fases do pensamento fenomenológico de Ludwig Revista Natureza Humana, São Paulo, v.22, n.1, pp.123-152, 2020. 
Binswanger. Psicologia em Estudo, 18(4), 679-687.

Ribeiro, C.V. (2008). Freud se encaixaria no rol dos operários (Handwerker) das ciências naturais? Considerações heideggerianas acerca da psicanálise freudiana. Aprender: Caderno de Filosofia e Psicologia da Educação. (10), 123-158.

Ribeiro, C.V. (2014). Freud e o methodenstreit: um debate a partir dos Seminários de Zollikon. Revista Diálogos Possíveis, 13(2), 97-122.

Richardson, W.J. (2003). Heidegger and Psychoanalysis? Natureza Humana, 5(1), 9-38. Ricoeur, P. (1965). De l'interprétation: essai sur Freud. Paris: Éditions du Seuil. Rocha, Z. (2000). Os destinos da angústia na psicanálise freudiana. São Paulo: Escuta. Rocha, Z. (2004). Freud e a filosofia alemã na segunda metade do século XIX. Síntese, 33(99), 45-64.

Santos, E.S. (2005). O conceito de angústia no pensamento pós-metafísico. Revista de Filosofia, 17(20), 45-66.

Santos, E.S. (2010). Winnicott e Heidegger: aproximações e distanciamentos. São Paulo: DWW Editorial; FAPESP.

Siewert, C. (2012). Consciência. In: Dreyfus, H.L; Wrathall, M.A. (Orgs.). Fenomenologia e Existencialismo (pp. 83-93). São Paulo: Edições Loyola.

Simanke, R.T. (2003). A letra e o sentido do "retorno a Freud" de Lacan: a teoria como metáfora. In: Safatle, V. (Org.). (pp. 277-303). Um limite tenso: Lacan entre a filosofia e a psicanálise. São Paulo: Editora Unesp.

Stolorow, R.D. (2006). The relevance of Freud's concept of danger-situation for an intersubjective-systems perspective. Psychoanalytic Psychology, 23(2), 417-419.

Stolorow, R.D. (2007). Trauma and Human Existence: Autobiographical, Psychoanalytic, and Philosophical Reflections. New York: Routledge.

Stolorow, R.D. (2011). World, affectivity, trauma: Heidegger and post-cartesian psychoanalysis. New York: Routledge.

Stolorow, R.D. (2015). A phenomenological-contextual, existencial, and ethical perspective on emotional trauma. Psychoanalytic Review, 102(1), 123-138.

Svenaeus, F. (2000). Das unheimlich - toward a phenomenology of illness. Medicine, Health Care and Philosophy, 3, 3-16.

Warsop, A. (2011). The ill body and das Unheimlich (the uncanny). Journal of medicine and philosophy, 36, 484-495.

Zahavi, D. (2015). A fenomenologia de Husserl (M. A. Casanova, Trad.). 1.ed. Rio de Revista Natureza Humana, São Paulo, v.22, n.1, pp.123-152, 2020. 
Janeiro: Via Verita.

Revista Natureza Humana, São Paulo, v.22, n.1, pp.123-152, 2020. 